Geopolítica(s) Revista de estudios sobre espacio y poder ISSN: 2172-3958

https://dx.doi.org/10.5209/geop.69149

\title{
Espacialidad y pandemia: la crisis del coronavirus vista desde la geopolítica negativa
}

\author{
Federico José Saracho López ${ }^{1}$
}

Recibido: 1 de mayo de 2020 / Aceptado: 10 de mayo de 2020

Resumen. La pandemia de COVID-19 que trastoca miles de cotidianeidades a nivel global se ha convertido en un paradigma para comprender las formas en que se articula el sistema-mundo, en virtud de la capacidad que ha tenido para sumirlo en una profunda crisis. El presente artículo propone la pertinencia de reflexionar a través de la geopolítica negativa las implicaciones de la dispersión del virus. Dicha propuesta se articula en seis ejes principales: la producción del espacio, las relaciones de poder transescalares, los procesos de dominación y violencia, la concreción del sistema-mundo, el análisis de espacios geoestratégicos y el reconocimiento de espacios negativos. Se considera que esta metodología permite otorgar tanto claridad a la crisis, como horizontes de cambio significativos.

Palabras clave: pandemia de COVID-19; geopolítica; negatividad; producción del espacio; sistemamundo.

\section{[en] Spatiality and Pandemic: The Coronavirus Crisis seen from Negative Geopolitics}

\begin{abstract}
The COVID-19 pandemic that disrupts thousands of everyday lives around the world has become a paradigm for understanding the ways in which the world-system is articulated, by virtue of its capacity to plunge it into a deep crisis. This article highlights the relevance of reflecting, through negative geopolitics, on the implications of the dispersion of coronavirus. This proposal is articulated in six main axes: The production of space, the cross-scale power relations, the processes of domination and violence, the concretion of the world-system, the analysis of geostrategic spaces and the recognition of negative spaces. We consider that this methodological approach allows both clarity to the process to the crisis and significant horizons of transformation.
\end{abstract}

Keywords: COVID-19 pandemic; security; geopolitics; negativity; production of space; worldsystem.

1 Colegio de Geografía, Facultad de Filosofía y Letras, Universidad Nacional Autónoma de México.

E-mail: fsaracho@comunidad.unam.mx 


\title{
[pt] Espacialidade e pandemia: a crise do coronavírus vista a partir da geopolítica negativa
}

\begin{abstract}
Resumo. A pandemia de COVID-19, que interrompe milhares de eventos cotidianos em todo o mundo, tornou-se um paradigma para entender as maneiras pelas quais o sistema-mundo é articulado, em virtude da capacidade que teve para mergulhá-lo em uma profunda crise. Este artigo propõe a relevância de refletir, através da geopolítica negativa, sobre as implicações da propagação do vírus. Essa proposta está articulada em seis eixos principais: a produção do espaço, as relações de poder em escala global, os processos de dominação e violência, a concretização do sistema-mundo, a análise de espaços geoestratégicos e o reconhecimento de espaços negativos. Considera-se que essa metodologia fornece clareza à crise e horizontes significativos de mudança.
\end{abstract}

Palavras-chave: pandemia da COVID-19; seguridade; geopolítica; negatividade; produção espacial; sistema-mundo.

Sumario. Introducción. 1. Sobre la producción del espacio. 2. Relaciones de poder territorializadas y transescalares. 3. La dominación y la violencia como ejes de análisis. 4. Sistema-mundo, hegemonía y desarrollo desigual desde la geopolítica. 5. Espacios estratégicos y geopolítica. 6. La búsqueda y el reconocimiento de espacios negativos. Reflexiones finales. Referencias.

Cómo citar: Saracho López, F. J. (2020). Espacialidad y pandemia: La crisis del coronavirus vista desde la geopolítica negativa. Geopolítica(s). Revista de estudios sobre espacio y poder, 11 (Especial), 69-79.

\section{Introducción}

Vivimos tiempos de profunda incertidumbre. Desde finales del año pasado hemos visto como la dispersión del coronavirus SARS-CoV-2, causante de la enfermedad COVID-19, ha escalado progresivamente, siendo declarado una pandemia a principios del marzo pasado. Las noticias que en un principio reportaban la situación en espacios lejanos ahora espejean las de nuestra realidad. Para el 27 de abril de este año ya había 3158922 casos confirmados, de los cuales 227940 habían perdido la vida (BBC, 2020). Al observar como la enfermedad alcanza nuevos territorios a medida que pasan los días, el mundo que pareciera expandirse por la pandemia a nosotros nos confina. Algunos estamos encerrados en nuestros hogares como medida de seguridad, con una profunda incertidumbre sobre el futuro. Aunado a ello, las medidas de mitigación han provocado una crisis económica a nivel global, donde se estima que 195 millones de personas perderán su empleo (Martínez, 2020). El mundo cambiará al terminar esta coyuntura, sin duda. Sin embargo, la pandemia también ha servido para dar cuenta de las formas en que actualmente éste se construye. Ello nos invita a reflexionar desde la geopolítica sobre la crisis que ha desatado el brote mundial de coronavirus. Durante varios años, hemos mantenido la agenda de desarrollar una forma diferente de geopolítica crítica, que contemple la producción del espacio y el desarrollo de asimetrías estructurales guiadas por el poder efectivamente ejercido. Consideramos que esta situación es la oportunidad de realizar un análisis para ponerla en práctica. Nuestra propuesta metodológica, más que crítica, se construye como negativa, ya que se niega a someterse a la epistemología que alimenta la geopolítica imperial y tradicional, sin separarse de la relación entre el concepto y la realidad como tal (Marcuse, 1986). La negatividad 
epistemológica se basa en interpretar "lo que es" en términos de "lo que no es", confrontando los hechos dados con lo que excluyen. El papel de la negación en la epistemología de la espacialidad depende de que reconozcamos esa negación como un acto positivo. Bajo esta lógica, la negatividad nos invita a observar que, al investigar el conflicto geopolítico en términos de la epistemología dominante, en realidad lo estamos deformando y falsificando (Marcuse, 1994).

La geopolítica negativa se proyecta en dos canales. Por un lado, niega la epistemología que brinda apoyo ideológico a la modernidad capitalista, denunciando a quienes, al afirmarla y anteponerla a cualquier otra opción de interpretación, excluyen cualquier construcción alternativa que no se ajuste a sus límites. Por otro lado, busca en la construcción de su análisis las contradicciones sistémicas que no solo niegan lo que afirma la modernidad capitalista, sino que en su acción sirven de ejemplo para iluminar la posibilidad de una praxis, entendida como una práctica consciente de transformación de una realidad histórica, cuyo movimiento se guía por una serie de valores que constituyen una crítica de esa realidad a transgredir (Saracho, 2017).

A continuación, desarrollaremos someramente los ejes de análisis a partir de los cuales puede construirse esta forma de geopolítica enmarcándola en nuestra reflexión en torno a la pandemia.

\section{Sobre la producción del espacio}

El proyecto de la geopolítica negativa tiene como piedra de toque la noción de espacio propuesta por Henri Lefebvre. Primero, porque el concepto de espacio no puede ser circunscrito solamente al campo epistemológico (Lefebvre, 1976), sino que de hecho en su materialidad precede a toda representación y sin embargo es construido y reformulado a partir de ellas. Además, es también un instrumento político cuya morfología está sujeta a las relaciones de poder que lo estructuran y que a su vez se sirven de él para estructurar la sociabilidad que las reproduce. El Estado, la clase dominante, los tecnócratas, o cualquier grupo que desee cristalizar su dominación, todos ellos producen espacio, al mismo tiempo que son producidos por éste para obtener asimetrías estratégicas que habiliten el control de los colectivos, como redes, flujos o circuitos (Raffestin, 2013). Todos ellos lo representan según sus intereses, instrumentalizándolo, y todos están relacionados con la manera en la que el espacio existe materialmente.

En relación con la pandemia, podemos ver lo anterior reflejado en diferentes expresiones. Una de ellas es en su dispersión, donde las vías espacio/tiempo que canalizan los flujos de la cotidianeidad y los circuitos de movimiento ligados a la vida diaria, se convierten en los principales puntos de contagio por la forma de su diseño y ordenamiento (Saracho, 2018). Precisamente porque están pensados para mantener el control poblacional a la par que habilitan el tránsito masivo para la reproducción sistémica, lo que la pandemia nos demuestra es lo que siempre estuvo presente: son espacios que están planeados para generar vulnerabilidad en los cuerpos de los sujetos a favor del sistema. Las avenidas, el trasporte público, las plazas y los centros comerciales, entre muchos otros, están instrumentados para mantener las relaciones tiempo/ espacio en detrimento de la vida, siendo a veces sofocantes, concentrándonos y negándonos movimiento y apertura. Dicho diseño ahora se re- 
vierte contra el sistema mismo al convertirse en la principal amenaza para la base de la reproducción: nosotros mismos. Si dicha condición no nos es siempre visible, es porque la representación está siempre al servicio de una estrategia, a la par que la oculta bajo una aparente coherencia racional y objetiva (Lefebvre, 1976). En este sentido, la pandemia también nos devela cómo el espacio es instrumental en el disciplinamiento de los cuerpos, expresado en su confinamiento: en todo momento existe la posibilidad de que los sujetos sean "guardados", compartimentalizados sea como individuos o como unidad familiar, lo que significa la inmanencia de una bioespacialidad en el diseño, que está lista para privar, a razón de la estrategia, al sujeto de su movimiento. Es lo no dicho dentro de la Carta de Atenas (Le Corbusier, 1993). La vivienda es: tanto el espacio material que representa "lo privado" del sujeto que la habita y que éste asocia con su trabajo, como el vehículo por el cual el sistema produce su contención.

\section{Relaciones de poder territorializadas y transescalares}

La crisis provocada por la COVID-19 nos lleva necesariamente a la reflexión del orden material. Las nociones de "dentro" y "fuera" en un orden discursivo o una representación no se manifiestan sólo en la palabra, se marcan en el espacio. No es casualidad que ambas ideas se construyan, de hecho, como una formulación de "lugar" respecto de sí. Se debe dotar de un orden físico a la idea o discurso para que se reproduzca a futuro. Neil Smith (2008) propuso la tesis de que el capitalismo da forma a su propia naturaleza para sobrevivir. ¿No es el orden estratégico que sus actores dan al espacio un factor vital para la formación de dicha naturaleza? ¿No es construir una naturaleza propia, la manera de hacer empatar la representación y la materialidad de forma artificial en el proceso de producción del espacio? ¿No es este el acto ideológico definitivo? Desde esta perspectiva, el espacio del capitalismo es fundamentalmente perverso. Esta lógica es central para entender la pandemia. La crisis económica que le acompaña es provocada por la desaceleración del movimiento de la cotidianidad, de la stasis de la forma "natural" del mundo del capital.

Pero la crisis fue provocada, a su vez, por dicho movimiento, como mencionamos anteriormente, ampliado a todas sus escalas. El contagio se genera de cuerpo a cuerpo, pero para llegar al momento en que vivimos, para que pasara de Wuhan a Roma, a Teherán, a Seúl, y así sucesivamente, se requiere el movimiento de varios cuerpos en cotidianidades que impliquen desplazamientos espacio/tiempos más agudos. La "pandemia" es una condición cuya lógica se construye a escala global, pero que para su concreción en realidad se movió de manera simultánea en todas las demás escalas. De Roma se extiende tanto a Milán como a Sinaloa (México). La pandemia es global, porque la globalidad se construye también dentro de lo cotidiano. La escala es espacio producido, no como forma vertical, sino como mosaicos a "ras de suelo" (Brenner, 2001). Las relaciones de poder se encuentran territorializadas en el espacio y éste no se construye en una sola escala. La geopolítica crítica cae en el error de intentar construir su lógica desde la escala global, salvo en algunas excepciones (Dalby, 2003; Slater, 2004). Sin embargo, este ir y venir entre las diferentes escalas nos ayuda a entender las estrategias de manera radicalmente diferente, así como las contradicciones o resistencias dentro de él. En lo que 
refiere a esta pandemia, el discurso busca mantener un epicentro que provoque un "afuera". Por poner un ejemplo: para la escala global, viene de China, posteriormente de EE UU. En la representación nacional, para el caso de México será Sinaloa o será la Ciudad de México. Para ésta última, el epicentro será la Alcaldía Gustavo A. Madero (GAM) o Iztapalapa. El mal está presente, pero a la vez "está afuera". Así se mantiene hasta el posible momento del contagio. Este ejercicio en realidad no refleja el comportamiento de la dispersión del virus, sólo refleja el lugar de enunciación y que a su vez manifiesta la jerarquía de las representaciones espaciales, así como la garantía de su reproducción. Por ello, es una herramienta discursiva utilizada por innumerables actores políticos. Materialmente hablando, la pandemia transita de forma transescalar, respondiendo tanto a la densidad poblacional, como a centralidades políticas, como a las rutas críticas de la comunicación que construyen la cotidianidad global, ignorando toda línea o frontera que demarca y da nombre a las expresiones poligonales anteriores. Hay lugares en China, EE UU, Sinaloa, Ciudad de México, GAM o Iztapalapa que nunca estarán propiamente "dentro" de la pandemia. En este sentido, la dispersión del virus funciona parcialmente como un tinte que permite ver las "arterias y venas" del sistema del capital desde una estructura multinivel. Es importante hacer hincapié en su parcialidad, pues también depende en gran medida de la actuación y mediación de diferentes actores e instituciones, gubernamentales y no gubernamentales, que pueden minimizar o aumentar el número de contagios, como en el caso de Suecia o el de los Estados Unidos.

\section{La dominación y la violencia como ejes de análisis}

Las articulaciones asimétricas en la producción del espacio tienen consecuencias claras que son expresadas mediante el enorme abanico que se abre en torno a la dominación y la violencia. La dominación objetiva al sujeto dentro de las dinámicas que norman la reproducción del poder, de sus reglas y su espacialización. Ello se refleja plenamente en el "estado de excepción" en el que la crisis sanitaria nos coloca: tanto por el control biopolítico que nos observa como "valores estadísticos" para procurar el menor índice de daño posible, como en nuestra posición vulnerable ante la emergencia por carecer del acceso indiscriminado a los servicios médicos y sanitarios a razón de dicho control. No es nuestra intención minimizar los esfuerzos de los equipos de salud por atender a aquellas personas que están contagiadas. Todo lo contrario, tienen nuestro más alto respeto, sobre todo por el riesgo que ellos mismos corren. Ellos también son objetivados por la dominación, pues se presupone su sacrifico. Sin embargo, la falta de capacidad para afrontar la pandemia, así como las condiciones en el que se desarrolla el problema mismo, son resultantes de nuestro modelo de sociabilidad. Esta doble forma de dominación nos da un resultado: la constante amenaza a nuestra nuda vida siempre ha estado ahí. La voluntad del sujeto es subsumida para la obtención de un orden regulatorio social que implica la perpetuación de la asimetría, a esto lo llamaríamos violencia (González Luna, 2017). La pandemia se abre claramente a los órdenes en que dicha violencia es ejercida. La propuesta apunta a observar dicha violencia no como una disrupción del orden social, sino como una mediación que de hecho lo garantiza y reproduce. González Luna (2017) invita a pensar el vínculo entre la violencia es- 
tructural y la producción espacial a través de tres vectores fundamentales: valorización del espacio, rentas culturales espacializadas y la conformación de dispositivos de regulación y control espacial, cuya materialización puede ser abordada desde la segregación socioespacial y la insularidad urbana.

Dichas formas de segregación y de control expresadas en estas tres dimensiones se ven reflejadas también dentro de la pandemia. Los sujetos en espacios segregados, que se expresan en contradicciones de clase, raza y género, tienden a tener un índice mayor de mortandad dentro de la crisis sanitaria. Este es el caso de Chicago, donde para el 6 de abril, habían muerto 1824 afroamericanos, frente a 847 blancos, 478 latinos y 126 personas de origen asiático. También es visible en el estado de Michigan, "donde los afroamericanos conforman solo el 14\% de la población, pero acumulan el 33\% de los casos reportados de COVID-19 y el 41\% de las muertes" (Serrano, 2020). Hablamos no solamente de orden y conflicto, sino de la vincolisación del sujeto, en el sentido de Perry Anderson, es decir, de la manera en que se le obliga estructuralmente a permanecer en el espacio que se construye específicamente para su tipo de sujeto objetivado, vulnerándolo (Saracho, 2019). "Lo geopolítico es evidente en la praxis que los sujetos particulares despliegan en órdenes espaciales específicos" (León Hernández, 2016, p.148). Por ello, la pandemia nos demuestra como el quehacer de la geopolítica debe voltearse de cabeza y volver al cuerpo como la primera escala de reflexión, pues este representa tanto el "punto 0" del desarrollo geográfico desigual como del orden socioespacial. La COVID-19 nos muestra esa brutalidad, cuando la ciudad global más importante, Nueva York, es tanto el nodo central de la globalización como un espacio desbordado que requiere fosas comunes debido a la enorme vulnerabilidad de sus habitantes ante la crisis. Ambas expresiones, desde el punto de vista sistémico, son interdependientes.

\section{Sistema-mundo, hegemonía y desarrollo desigual desde la geopolítica}

Consideramos que la pandemia difícilmente significa una "desglobalización". Nunca debe de perderse de vista que todo análisis se encuentra enmarcado dentro del sistema-mundo: una unidad con una división del trabajo única y con múltiples sistemas de representación (Wallerstein, 2000). Esto significa que las contradicciones del espacio son espejos que reflejan las contradicciones propias del capitalismo: la dialéctica entre la homogeneidad y lo fragmentado, la globalidad y su pulverización, entre el espacio producido por el sistema económico (world-economy) y la territorialización producida por el sistema político. La pandemia es un reflejo del propio sistema-mundo. Como se sabe, el desarrollo en el capitalismo no es la falta de atraso, sino el subdesarrollo del "otro", que hace el papel de dominado. Tanto es así que esa observación puede ser realizada a cualquier escala y mantenerse como válida: la producción del espacio en el sistema-mundo desarrolla asimetrías para subsistir. Ello significa la construcción de policentros y poliperiferias transescalares dentro del sistema, que se demuestra tanto en el alto número de contagios de las zonas centrales, que concentran los factores del capital, como en la crisis económica subsecuente, en donde las espacialidades dependientes se encuentran en particular vulnerabilidad en la medida en que sus economías se interconectan de forma asimétrica, lo que ha impedido su diversificación. A manera de ejemplo, podemos verlo desde la región de América del Norte, donde la dependencia de las economías 
de México y Centro América a la de Estados Unidos, se traduce en una incapacidad de mantener estabilidad en tanto no se reactiven los circuitos de la economía del vecino del Norte. Así, mientras que los centros presentan en este momento un mayor número de contagios, las periferias y semiperiferias, al haber entrado posteriormente a la fase de dispersión del virus, afrontarán esta con economías muchísimo más debilitadas que las centrales. Este desfase espacio/tiempo reafirma la asimetría estructural.

La pandemia a futuro puede facilitar la degradación de alguna fuente de valor, como por ejemplo la sobreexplotación de la fuerza de trabajo, que ofrecerán los espacios dependientes para permitir su restructuración económica, aumentando la capacidad de acumulación de las centralidades, acelerando nuevamente las economías de estas. Este ejercicio encontrará ecos en cualquier escala, si bien no se expresará en la misma forma. Anclar, espacializar, la geopolítica en el pensamiento crítico refiere directamente a reconocer la lucha de clases. Esta observación se conecta directamente con las formas de dominación y violencia que veíamos en el apartado anterior, pues estamos hablando de la base estructural de la sociedad capitalista que viabiliza su reproducción, tanto discursiva como material; hablamos de un sujeto, hablamos nuevamente de su cuerpo, de su género, de su "raza", pero todo ello cambia radicalmente cuando a su vez se le ubica en una clase social. Lo mismo pasa con la territorialización, observamos el sentido de clase estratégico que existe en su interior para poder mantener su espacio funcionando dentro de la división del trabajo; que se construye desde la relación local, con los territorios "otros", aledaños, hasta la relación global con el sistema en sí. Al abrir las escalas, al tiempo que se mantiene el pensamiento dialéctico como espina dorsal, se hace posible comprender la interconexión del conflicto en todas sus aristas, en toda su compleji$\mathrm{dad}$, sin fragmentar la riqueza de sus diferentes dimensiones.

Entre el orden de lo discursivo y de lo material es que se levanta la construcción hegemónica. La realización del aparato hegemónico depende no solamente de la capacidad de ejercer violencia directa, sino también de la creación de un terreno ideológico, de un mosaico de representaciones y de formas específicas de construcción del conocimiento que introducen una nueva moralidad de conformidad con la concepción de mundo que dicho mosaico "representa" a beneplácito del sistema de orden que busca implantar (Herrera, 2016). Bajo esta óptica, tenemos que dejar claro que no creemos que la pandemia signifique el fin de la hegemonía en sí, pues sus órdenes ideológicos y de representación no están siendo contestados de forma particular. Lo que se encuentra en disputa, por un número cada vez mayor de personas, es el sistema civilizatorio completo. Sin embargo, aún no es una tendencia generalizada, por lo que la hegemonía no puede considerarse en detrimento. Todo lo contrario, se refirma dentro de la recuperación del Estado como "público hegemónico", en la idea del libre mercado como el garante del bienestar, y en la sociedad civil como expresiones dependientes a ambas. En todo caso, lo que observamos es la disputa por el papel de sujeto dominante dentro de la hegemonía, es decir el sujeto colectivo que estratégicamente se aprovecha de los contornos de esta para afirmar su capacidad de ejercer el poder (Ceceña, 2018). Dicho sujeto, la élite política/económica de los Estados Unidos, encuentra una disputa real a su dominio hegemónico por su contraparte china, como se ha visto en la rearticulación de los mercados globales, siendo la crisis del petróleo su momento paradigmático hasta este momento. Sin embargo, cabe acarar que dicha disputa solo reafirma el carácter 
práctico e instrumental, no sólo de la actual hegemonía, sino del sistema-mundo en sí.

\section{Espacios estratégicos y geopolítica}

La idea de la construcción de "espacios estratégicos" puede convertirse en un fetiche para la investigación en geopolítica, debido al peso toral que tenía dentro de las tradiciones clásicas. La geopolítica negativa tiene que reconocer su existencia, a pesar de entenderlos de manera radicalmente diferente. El diseño del espacio instrumental tiene como resultado patrones geopolíticos de producción, que en sí mismo sostienen la dinámica del sistema-mundo. En ellos, ciertos lugares juegan un papel más delicado, dependiendo de la estrategia a la que responden, al tiempo que reproducen las contradicciones y las situaciones propias del capitalismo (Herrera, 2017).

Son diferentes los puntos geoestratégicos que pueden interpretarse en función a la pandemia, tanto en su dispersión como en su combate. Prueba de ello es la ciudad de Wuhan, que funcionó como el supuesto epicentro del brote, a la par que jugó un papel clave en la estrategia de contención, al aplicarse medidas especiales de confinamiento ciudadano para reducir la expansión del coronavirus. Los puntos geoestratégicos no son puntos fijos, no tienen una capacidad "estratégica" inherente. Dependen en gran medida de los actores que estén generando dicha estrategia, de las condiciones espacio-tiempo en el que se enmarcan y de su "lugar" sistémico en el tejido del sistema-mundo. En función a ello, cada actor toma la decisión de cuáles son los lugares que se mantendrán cerrados, cuáles serán las actividades que se permitirá realizar, tomando en cuanta las posibilidades del espacio materialmente producido. Para este momento Wuhan ya no puede ser considerado un espacio geoestratégico a la luz de la pandemia, siendo ahora Nueva York, por ejemplo, más relevante para pensar la crisis.

\section{La búsqueda y el reconocimiento de espacios negativos}

Si buscamos separarnos de la epistemología dominante de la geopolítica tradicional e imperial y tenemos el afán de hacerlo a partir de la observación de la materialidad y no solamente desde su representación, daremos cuenta de que existen formas contestatarias de espacialización que emanan de aquellos a los que Walter Benjamin (1999) caracterizaba como vencidos; espacios estructurados por la clase dominada en la concreción de una salida, no solamente de su situación de clase, sino del sistema mismo que la produce, donde se territorializa un nuevo orden simbólico en el cual la situación que provocó la asimetría es imposible. Dichos espacios de contradicción son los que hemos bautizado como "espacios negativos" (Saracho et al., 2016), que hacen estallar los hechos dados y subvierten la construcción de la realidad. En otros términos, León Hernández apunta a la importancia de descifrar "las prácticas geopolíticas [...] en la acción transformadora de los sujetos políticos que busquen alterar su espacialidad, ya sea concibiendo un proyecto para hacerlo o bien llevando a cabo una reconfiguración espacial efectiva" (2016, p.138). 
Si bien en otras ocasiones hemos hablado del Confederalismo Democrático en Rojava o del EZLN como ejemplos claros, dentro de esta pandemia encontramos que, ante la multidimensionalidad de la crisis empezamos a ver estrategias comunitarias de solidaridad que claramente demuestran expresiones de negatividad dentro de su constitución. Desde redes solidarias de comercio justo que conectan directamente a los productores, o grupos de apoyo que arriesgan su vida para alcanzar a personas vulnerables, e incluso el surgimiento de redes barriales de autoprotección y defensa, se han configurado de manera efectiva, globalmente desde lo local, en el silencio que provoca la desaceleración del sistema.

Estamos ante la apertura de diversas praxis creadoras, que nos llevan a ir más allá de la representación. Las expresiones de la negatividad son expresiones creativas, poiéticas, de la producción del espacio, que solamente puede ser construidas desde la contestación, abriendo el espectro epistemológico de nuestra geopolítica.

\section{Reflexiones finales}

En un mundo donde la esfera interior del capital se ha cerrado, siendo la globalización la culminación de su proyecto imperial (Sloterdijk, 2010), la pandemia del coronavirus no significa que su desaceleración y crisis signifique su desmantelamiento, sino más bien su reordenamiento. Tampoco nos deja otra opción más que observar la cara oculta del proceso. Parece entonces que nuestra cotidianeidad y nuestra normalidad se verán tanto trastocadas como reconfiguradas, pues el sistema del capital es también sumamente hábil para rearticularse en aras de mantenerse en pie. Por ello los dispositivos de dominación del sistema-mundo se afirman dentro de los conflictos. Sin embargo, la dialéctica bien nos dice que cuando se completa una totalización, inmediatamente surgen contradicciones que cargan en ellas el principio de esperanza. La virtud de la geopolítica negativa es que puede observar cómo se configura un espectro contestatario de naturaleza transescalar, para visibilizarlo y así mantener abierta la posibilidad de cambio en miras a otra modernidad más incluyente y justa. En la contradicción que hay dentro del propio sistema, existe la creación de otro mundo posible.

Consideramos que tanto para nosotros en la academia, como para el público en general, debe existir un claro compromiso dentro de esta crisis, tanto en la denuncia de las formas estructurales de la dominación, como para la creación de nuevas representaciones a partir de la observación de lo materialmente presente, de las experiencias que estamos transitando en este "instante de peligro" y que demuestran que un mundo mejor no sólo es posible, sino que se construye continuamente en nuestra experiencia. En ello reside la verdadera fuerza de una geopolítica "desde abajo".

\section{Referencias}

BBC. (2020). Coronavirus: el mapa que muestra el número de infectados, muertos y recuperados en el mundo por COVID-19. $B B C, 27$ de abril. Recuperado de https://www.bbc.com/mundo/noticias-51705060

Benjamin, W. (1999). Ensayos escogidos. México: Ediciones Coyoacán. 
Brenner, N. (2001). The limits to scale? Methodological reflections on scalar structuration. Progress in Human Geography, 25(4), 591-614.

Ceceña, A. E. (2018) Hegemonía, poder y territorialidad. En D. Herrera, F. González Luna y F. Saracho (Coords.), Espacios de la dominación. Debates sobre la espacialización de las relaciones de poder (pp.19-37). México: FFyL-UNAM.

Dalby, S. (2003). Environmental Geopolitics - Nature, Culture, Urbanity. En K. Anderson et al. (Eds.), Handbook of Cultural Geography (pp.498-509). Londres: Sage.

González Luna, F. (2017). Pensar la violencia: espacios homogéneos vacíos. En D. Herrera, F. González Luna y F. Saracho (Coords.), Apuntes teórico-metodológicos para el estudio de la espacialidad: aproximaciones a la dominación y la violencia. Una perspectiva multidisciplinaria (pp.77-101). México: Facultad de Filosofía y Letras (FFyL)Universidad Nacional Autónoma de México (UNAM) / Ediciones Monosílabo.

Herrera, D. (2016). Hegemonía, poder y crisis. Bifurcación, espacialidad estratégica y grandes transformaciones globales en el siglo xxi. México: FFyL-UNAM / Ediciones Monosílabo.

Herrera, D. (2017). Espacios estratégicos y hegemonía mundial: dominación de espectro completo, espacios comunes y supremacía geoestratégica estadounidense. En P. Gómez y F. González (Coords.), Discusiones desde la geografía (pp.21-51). México: FFyLUNAM / Ediciones Eón.

Le Corbusier. (1993). Principios de urbanismo (La Carta de Atenas). Barcelona: PlanetaAgostini

Lefebvre, H. (1976). Espacio y política. El derecho a la ciudad II. Barcelona: Península.

León Hernández, E. (2016). Geografía crítica. Espacio, teoría social y geopolítica. México: FFyL-UNAM / Itaca.

Marcuse, H. (1994). Razón y revolución. Barcelona: Atalaya.

Marcuse, H. (1986). Ensayos sobre política y cultura. Barcelona: Planeta-Agostini.

Martínez, M. (2020). En riesgo, 195 millones de empleos en el mundo durante el II trimestre. El economista, 7 de abril. Recuperado de https://www.eleconomista.com.mx/empresas/OIT-preve-perdida-de-mas-25-millonesde-empleos-en-el-mundo-por-Covid-19-20200407-0056.html

Raffestin, C. (2013). Por una geografía del poder. México: El Colegio de Michoacán / Fideicomiso Felipe Teixidor y Monserrat Alfau de Teixidor, Zamora.

Saracho, F. (2017). (Re)pensar la geopolítica crítica. Un pequeño manifiesto desde la negatividad. En E. León Hernández (Coord.), Praxis espacial en América Latina. Lo geopolítico puesto en cuestión (pp.153-180). México: FFyL-UNAM/Itaca.

Saracho, F. (2018). La ciudad y el poder. Hacia una comprensión geopolítica de la ciudad. Academia XXII, 9(17), 18-44.

Saracho, F. (2019). Sobre el espacio de la identidad. La fabricación de la nación y la geopolitica de su contradicción. México: FFyL-UNAM / Ediciones Monosílabo.

Saracho, F., Herrera, D., y González Luna, F. (2016). Espacios negativos: la construcción de espacios utópicos como resistencia política y su territorialización. En N. Benach et al. (Eds.), Actas del XIV Coloquio Internacional de Geocrítica. Las utopías y la construcción de la sociedad del futuro (pp.1-18). Barcelona: Universidad de Barcelona.

Serrano, C. (2020). Coronavirus en EE.UU. El devastador impacto del covid-19 entre los afroamericanos. $B B C, 8$ de abril. Recuperado de https://www.bbc.com/mundo/noticiasinternacional-52219474 
Slater, D. (2004). Geopolitics and the Post-Colonial. Rethinking North-South Relations. Londres: Wiley-Blackwell.

Sloterdijk, P. (2010). En el mundo interior del capital. Para una teoría filosófica de la globalización. Madrid: Siruela.

Smith, N. (2008). Uneven Development: Nature Capital, and the Production of Space. Athens: University of Georgia Press.

Wallerstein, I. (2000). The Essential Wallerstein. Nueva York: The New Press. 